\title{
Medievalista
}

Online

$28 \mid 2020$

Número 28

\section{LADERO QUESADA, Miguel Ángel - Ciudades de la España Medieval. Introducción a su estúdio. Madrid: Dykinson, 2019 (264 pp.)}

Paula Pinto Costa

\section{(2) OpenEdition}

Journals

Edição electrónica

URL: http://journals.openedition.org/medievalista/3367

DOI: 10.4000/medievalista.3367

ISSN: 1646-740X

Editora

Instituto de Estudos Medievais - FCSH-UNL

Edição impressa

Paginação: 391-396

Refêrencia eletrónica

Paula Pinto Costa, «LADERO QUESADA, Miguel Ángel - Ciudades de la España Medieval. Introducción a su estúdio. Madrid: Dykinson, 2019 (264 pp.)», Medievalista [Online], 28 | 2020, posto online no dia 01 julho 2020, consultado o 25 março 2021. URL: http://journals.openedition.org/medievalista/3367 ; DOI: https://doi.org/10.4000/medievalista.3367

Este documento foi criado de forma automática no dia 25 março 2021.

\section{c) (1) 8}

Mediavalista está licenciado com uma Licença Creative Commons - Atribuição-NãoComercial 4.0 Internacional. 


\title{
LADERO QUESADA, Miguel Ángel - Ciudades de la España Medieval. Introducción a su estúdio. Madrid: Dykinson, 2019 (264 pp.)
}

\author{
Paula Pinto Costa
}

\section{REFERÊNCIA}

Ciudades de la España Medieval. Introducción a su estúdio. Madrid : Dykinson, (264pp.)

1 Miguel Ángel Ladero Quesada traz a público uma síntese sobre cidades da Espanha medieval organizada em oito capítulos ilustrados e enriquecidos por um conjunto de vinte e oito plantas de cidades, na sua esmagadora maioria peninsulares, a que juntou outras, de centros urbanos centro-sul americanos. A estas soma-se um significativo conjunto de mapas, imagens, fontes documentais escritas e selos municipais, distribuídos ao longo da obra.

2 Neste livro começa por colocar a problemática das cidades na Idade Média, procurando traçar um enquadramento para a boa explanação do assunto. $O$ tema da história urbana tem colhido desde há muito o interesse dos investigadores e esta obra reflete o amplo conhecimento que o seu autor tem do mesmo. Move-se ao longo de uma cronologia bastante ampla, que se situa entre os séculos XI e XV. Reafirma que o século XI coincide com o renascimento urbano europeu, já apontado por inúmeros autores, abrindo-se a partir daí um tempo profícuo de fundação de cidades novas e de renovação da vida urbana. Embora estas delimitações cronológicas sejam válidas em termos gerais, a diversidade de áreas geográficas em que este estudo incide dá lugar a uma problematização destes limites e a uma necessária adequação a cada uma delas em concreto. A formação da rede urbana hispânica teve lugar entre 1060-1330, em sintonia com a conquista, ocupação e colonização do território e teve implicações no traçado 
urbanístico e no sistema económico das cidades. O livro incide sobre a Espanha, em sentido alargado, a Hispânia, deixando num plano secundário a emergência política dos vários reinos no contexto da reconquista, e acaba por fazer uma chamada de atenção para a realidade Quinhentista da América centro-sul pelo facto de poder ser considerado um espaço de prolongamento da cidade hispânica de tempos anteriores. Em termos gerais, são abordadas a organização urbanística, a dinâmica social, nomeadamente a multiplicidade das hierarquias e das possibilidades de mobilidade social, a ordenação jurídica, fazendo-se a distinção entre a tutela régia, a episcopal e a senhorial sobre diferentes cidades, e a dimensão religiosa e cultural dos espaços urbanos.

3 No primeiro capítulo, dedicado à discussão sobre regiões e cidades entre os séculos XI e $\mathrm{XV}$, é avançada uma geografia das mesmas que ultrapassa a espacialidade da Espanha continental, nesta obra seccionada em grandes áreas, a saber: o caminho de Santiago, compreendendo os focos de urbanização entre Jaca e Compostela, Castela e Leão, Portugal, Navarra, Aragão e Catalunha, incluindo ainda dados sobre Granada e as Canárias. As singularidades e os principais traços de cada uma destas áreas são apresentados de forma bastante sistematizada. Deste modo, o autor refere que no Caminho de Santiago apareceram novas cidades quase sempre de iniciativa régia e verificou-se a renovação e o crescimento de cidades pré-existentes, fatores que tiveram impacto na redistribuição da população e na atratividade das próprias cidades. Já para Castela e Leão, evidencia a importância da colonização com origem nos meios rurais e a consolidação dos meios urbanos que asseguravam a fronteira, reforçados com a concessão de foros e de privilégios jurídicos e económicos. A sul do Douro, nas áreas correspondentes a Castela e a Leão, é entendido que a cidade assumiu o papel de cabeça de uma "tierra, término o alfoz", tratando-se de um modelo hierarquizado, em que a colonização e a defesa do território eram prioritários. Em relação a Portugal, é valorizada a importância da tradição urbanística anterior e o papel da monarquia que, por vezes, concedeu a jurisdição sobre alguns núcleos urbanos, sobretudo às Ordens Militares. Já da Andaluzia e de Múrcia é reafirmado o aproveitamento das estruturas urbanas pré-existentes, não se justificando a fundação de novos núcleos em tempos medievais. Acrescenta que a organização destes centros urbanos se baseou na grande experiência obtida em situações anteriores de colonização de novos territórios e assentou na definição dos chamados repartimientos e de foros que favoreceram o governo desses núcleos, referindo que na zona mais a norte de Navarra e de Aragão apenas se registou o desenvolvimento decorrente do Caminho de Santiago, enquanto na Catalunha Vieja, a necessidade de demarcar os vários condados deu lugar à fundação ou à promoção de alguns núcleos urbanos. Faz notar que, em contraste, em Granada e nas Canárias, o fenómeno urbano em apreço revelou-se tardio. o reino de Granada foi conquistado pelos Reis Católicos, que tinham uma força política incomparável com a dos monarcas anteriores, razão pela qual o direito real terá sido a matriz do governo urbano.

4 O capítulo segundo é dedicado à inserção das cidades nas suas paisagens, enquanto indicador privilegiado da consciência da formulação da identidade da própria cidade. Topografia, morfologia e urbanismo são elementos essenciais para a sistematização que o autor nos proporciona. Assim, são alvo de reflexão a relação da cidade com os seus territórios envolventes, a sua articulação com a rede de caminhos, bem como algumas 
das preocupações com o espaço público e mesmo com a saúde pública no contexto urbano.

5 No capítulo três, a cidade é vista como centro económico, sendo salientada a articulação profunda com o mundo rural, tanto na perspetiva de que a cidade depende desse entorno, sobretudo por razões de abastecimento de alimentos, de matériasprimas e de população e, por consequência, de mão-de-obra, como o influencia e transforma, afirmando-se como centro dirigente e regulador do mercado na sua complexa globalidade. $\mathrm{O}$ artesanato e o comércio, atividades que se distinguiam na cidade, por vezes concentravam-se em algumas zonas do espaço urbano, o que contribuía para o seu dinamismo e singularidade e, também, para o estabelecimento de sociabilidades únicas nem sempre marcadas por relações pacíficas.

Por sua vez, no capítulo quatro, o autor fala sobre a ordem e as hierarquias sociais. Começa por insistir na profunda articulação entre os mundos urbano e rural, embora saliente as especificidades da economia urbana que influenciavam certos fenómenos ímpares de estratificação e de mobilidade social, contemplando tanto as franjas desse amplo espectro social, compostas por diversas elites e patriciados urbanos e pelos marginais, como os vizinhos, os judeus e os muçulmanos.

7 O papel desempenhado pela cidade no contexto do poder político constitui o objetivo do capítulo cinco. Explica-se que o direito local, plasmado em documentos que na generalidade se podem designar por foros e costumes, privilégios e ordenanças, foi adquirindo contornos cada vez mais elaborados. É também alvo de atenção a questão da autonomia municipal com base num recorte geográfico, e com um sentido evolutivo ao longo da cronologia em estudo. Neste capítulo são ainda focados os lugares de exercício do poder, bem como os títulos, símbolos e insígnias com que se punha de manifesto a imagem política da cidade e alguns traços da sua identidade.

8 As milícias concelhias e as estruturas defensivas, como muralhas e castelos, são os objetos centrais do sexto capítulo. Realça-se que a prestação de serviço com armas era crucial em tempos medievais peninsulares, sendo estas milícias parte integrante do exército régio, a par de outros corpos militares, o que as expôs a uma intervenção crescente por parte da monarquia. Em causa estava tanto a defesa da ordem pública, como a mobilização e a participação na guerra em territórios mais ou menos afastados, o que exigia esforços, por vezes conjuntos e que poderiam envolver mais do que uma cidade. Em cenários em que a guerra pontuava com alguma frequência, emergia a dimensão real e simbólica das estruturas defensivas.

9 A profunda relação entre a Igreja e a cidade é explanada no capítulo sete, parte da obra em que se destaca tanto a importância do fator eclesiástico ao nível da origem e das identidades de algumas cidades, como o papel socioeconómico do clero. Mostra-se que Sés catedrais e outros edifícios eclesiásticos foram pontos axiais dos mais diversos espaços urbanos e, frequentemente, veículos de transmissão de memórias escritas e de acervos documentais ímpares para a investigação histórica.

10 Por fim, no capítulo oitavo, é feito um apanhado sobre certos aspetos da cultura urbana e sobre a teoria da cidade em termos globais. Destacam-se a este nível a festa no espaço público, encabeçada pela procissão do Corpus Christi, o ensino em geral e a Universidade em particular, as retóricas literárias, iconográficas e cartográficas, domínios especiais de manifestação de aspetos simbólicos e de afirmação da identidade de algumas cidades. Sem que o livro inclua uma conclusão formal, este último capítulo aponta 
nesse sentido, sobretudo quando, a partir de algumas fontes históricas, se aproxima da teoria da cidade e da conceção da cidade ideal.

11 Curiosamente, o autor optou por atribuir ao livro o subtítulo "Introducción a su estúdio", alertando, ainda que de forma velada, para o facto de haver muito para estudar na temática em foco. Como suporte à presente obra e à prossecução da investigação sobre o tema em si mesmo, o livro conta com uma bibliografia seletiva, organizada em diferentes categorias temáticas e em várias áreas geográficas. Em síntese, o livro oferece uma excelente sistematização de dados históricos, alguns dos quais de natureza quantitativa, e proporciona uma explicação organizada e clara sobre as cidades da Espanha medieval, a qual é de grande utilidade no âmbito da historiografia ibérica.

\section{AUTORES}

\section{PAULA PINTO COSTA}

Universidade do Porto, Faculdade de Letras 4150-564 Porto, Portugal. ppinto@letras.up.pt. https://orcid.org/0000-0002-1926-2276 